Polymer Journal, Vol. 2, No. 5, pp 606-622 (1971)

\title{
Electron Spin Resonance Study of Polyethylene Irradiated with Ultraviolet Light
}

\author{
Kozo Tsuji and Toshifumi SeIKI \\ Central Research Laboratory, Sumitomo Chemical Co., Ltd. \\ Takatsuki, Osaka, Japan.
}

(Received February 10, 1971)

\begin{abstract}
ESR Spectrum of polyethylene irradiated with ultraviolet light at $-196^{\circ} \mathrm{C}$ was composed of a superposition of two six line spectra, whose total widths were about 155 and 110 gauss, respectively. Free radicals responsible for these two spectra are $-\mathrm{CH}_{2}-\dot{\mathrm{C}} \mathrm{H}-\mathrm{CH}_{2}-$ and $-\mathrm{CH}_{2}-\mathrm{CH}_{2} \cdot$. The latter radicals were very reactive and abstracted hydrogen atoms from other parts of polymers to produce former radicals. During the warm-up process, a sharp singlet spectrum appeared at about $-125^{\circ} \mathrm{C}$, which was

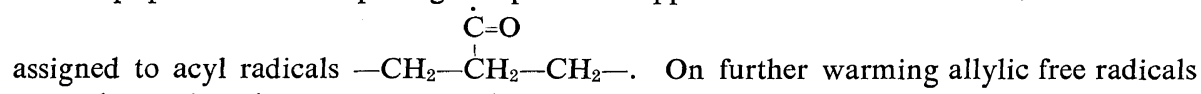
were observed at the temperatures above nearly $-30^{\circ} \mathrm{C}$. An increase of signal intensity was observed during the warm up process.

The primary process of photo-induced reactions in UV-irradiated polyethylene at $-196^{\circ} \mathrm{C}$ was thought to be a Norrish-type I reaction of the carbonyl group, and a production mechanism of free radicals is proposed.

The absorption spectrum of polyethylene film in $\mathrm{O}_{2}$ showed greater absorbance than that in $\mathrm{N}_{2}$, which could be attributed to the formation of charge-transfer complexes of polyethylene with oxygen molecules. It was also shown that the charge-transfer complexes participated in radical formation.

Photo-induced conversions of acyl radicals and peroxy radicals were also reported.

KEY WORDS Electron Spin Resonance / Polyethylene / Ultraviolet Irradiation/Radical Conversions/Alkyl Radical/Acyl Radical/Allylic Radical / Peroxy Radical /
\end{abstract}

In order to study a photodegradation mechanism of polymers, it is quite important to follow the behavior of free radicals as intermediate species. Electron spin resonance spectroscopy is a powerful method for detecting and identifying free radicals and elucidating their behavior. Electron spin resonance spectra of UV-irradiated polyethylene have been reported by several authors. ${ }^{1-8}$ Although the identifications by these authors have not necessarily coincided, main free radicals observed at $-196^{\circ} \mathrm{C}$ are thought to be alkyl radicals of the type $-\mathrm{CH}_{2}-\dot{\mathrm{C}} \mathrm{H}-\mathrm{CH}_{2}-$. There has been much discussion on the mechanism of radical formation but no clear conclusions have been drawn. ${ }^{9}$ It will be useful to discuss the mechanism incomparison with that in the case of ionizing radiation. ${ }^{10-12}$

In a previous paper, ${ }^{6}$ we reported that ESR spectra of UV-irradiated polyethylene depend on the pressure in the sample tube and it was tentatively attributed to a change in energy transfer mechanisms. This idea, however, has since been discarded owing to further detailed study. In this connection we want to report in this paper the identification of free radicals in irradiated polyethylene, their formation mechanism and their behavior on warming and after subsequent irradiation.

\section{EXPERIMENTAL}

Low- and high-density polyethylenes (Sumitomo Chemical Co., Ltd.) were purified by dissolving in boiling xylene, followed by precipitating in cold methanol and washing with $n$-hexane. The purified sample of polyethylene was pressed 
at $130^{\circ} \mathrm{C}$ and at $150^{\circ} \mathrm{C}$ for low- and high-density polyethylene, respectively, between stainless-steel frames, to give rod-shaped specimens 2-mm square, which were immersed in $n$-hexane for over two days. The samples were evacuated to $10^{-6} \mathrm{mmHg}$ in the sample tube at between $90^{\circ} \mathrm{C}$ and room temperature, and in most cases nitrogen gas was subsequently introduced at $1 \mathrm{~atm}$. Thin films for optical measurements were made similarly by pressing polyethetene between aluminum foil frames and immersed in $n$-hexane.

ESR spectra were recorded with an X-band spectrometer with $100-\mathrm{kc}$ field modulation (Japan Electron Optics Laboratory Co., Model JES, 3BS-X) during and after irradiation. Microwave power was about $1.6 \mathrm{~mW}$.

Ultraviolet irradiations were carried out in the ESR cavity with a Xenon short arc lamp. Its compartment has already been described. ${ }^{6}$ The wavelength of the light emitted from this lamp is between about $220 \mathrm{~m} \mu$ and $2 \mu$ with continuous distribution of intensity, which is very similar to that for solar radiation except for the region between 0.8 and $1 \mu$.

Several kinds of glass filters (Toshiba color glass filter) were used to measure the wavelength dependence of radical formation. The intensity of incident light was changed by using calibrated wire screens in order to examine the effect of the light intensity on the rate of radical formation.

It should be mentioned that the temperature of the sample rose somewhat during irradiation even though the sample tube was immersed in liquid nitrogen and a $3-\mathrm{cm}$ water layer was applied as a filter. The degree of rise, however, depends on the vacuum of the sample tube and the filters applied. When irradiation was made to the highly evacuated sample $\left(10^{-5} \mathrm{mmHg}\right)$ without any filters for $10 \mathrm{~min}$, the temperature at the center of the sample increased up to $-140^{\circ} \mathrm{C}$, although irradiation to the air-filled sample showed a temperature increase up to $-180^{\circ} \mathrm{C}$. After a UV-D25 filter was applied, the temperature increase was only $7^{\circ}$ and $0.5^{\circ}$ for the highly-evacuated and air-filled samples, respectively. This phenomenon may be caused by difference of thermal conductivity in the sample tube. A super high-pressure mercury lamp also caused a rise of sample temperature to a larger extent. In order to minimize this thermal effect by irradiation, most experiments were carried out by using nitrogen-filled samples and applying the UV-D25 filter.

Ultraviolet-absorption spectra were recorded at room temperature by a Perkin-Elmer 450 Spectrophotometer.

\section{RESULTS}

\section{Absorption Spectra of Polyethylene}

Absorption spectra of high-density polyethylene film $(0.20 \mathrm{~mm})$ in $\mathrm{N}_{2}$ and in $\mathrm{O}_{2}$ are shown in Figure 1. According to Partridge, ${ }^{13}$ the absorption which increases gradually from about $1 \mu$ to about $220 \mathrm{~m} \mu$, is due to surface or Rayleigh scattering of the sample and this is not a real absorption, and some absorptions observed in the region between 334 and $193 \mathrm{~m} \mu$ are attributed to carbonyl groups or some other oxidation products, which could be removed by immersing the sample in $n$-hexane. In the present case, besides the apparent absorption due to surface or Rayleigh scattering, a broad absorption was observed between 400 and $230 \mathrm{~m} \mu$ which could not be removed by $n$-hexane immersion. It is reasonable to attribute this absorption to some carbonyl groups contained in the polymer, and this could be confirmed by infrared spectroscopy $(1 \mathrm{C}=\mathrm{O} / 17000 \mathrm{C})$. They may be incorporated in the polymer during polymerization and manufacturing processes or by autoxidation.

Another noticeable point is a difference of the absorption spectra in $\mathrm{N}_{2}$ and in $\mathrm{O}_{2}$. The absorbance in $\mathrm{O}_{2}$ is greater than that in $\mathrm{N}_{2}$ at a wavelength shorter than about $270 \mathrm{~m} \mu$. Analogous difference has been observed for polypropylne and poly[3,3-bis(chloromethyl)oxetane]. ${ }^{9}$ Oxygen molecules themselves have no such an absorption in the near ultraviolet region as is obvious from the control experiment, although the Herzberg forbidden continuum has a very low-absorption coefficient in this region. The extra absorption in $\mathrm{O}_{2}$ can be attributed to the absorption due to charge-transfer complexes of polymers with oxygen molecules since similar absorptions observed for hydrocarbons, ${ }^{14,15}$ ether, ${ }^{14-16}$ amines,${ }^{15}$ and alcohols ${ }^{14,15}$ of low molecular weight are identified as due to the charge-transfer complexes of these compounds with oxygen. 


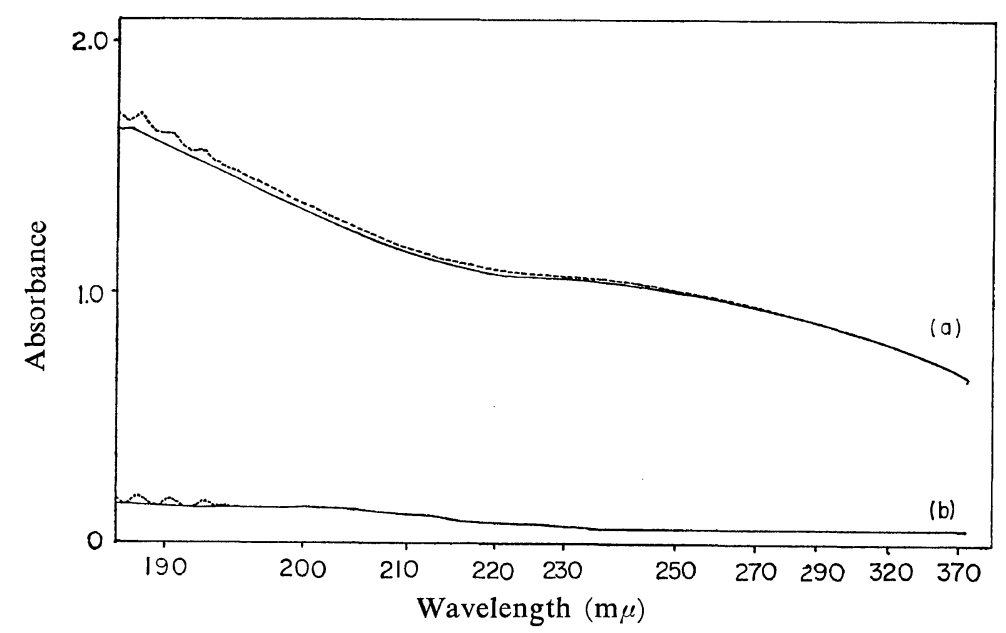

Figure 1. Ultraviolet absorption spectra of high-density polyethylene film $(0.20 \mathrm{~mm})$ : (a) polyethylene film in the quartz optical cell; (b) only the optical cell. Solid and dotted curves show the absorption spectra observed when nitrogen or oxygen gas respectively was introduced (1 atm) in the 1$\mathrm{cm}^{2}$ cell. Vibrational structures observed near $190 \mathrm{~m} \mu$ seem to be due to a part of Schumann-Runge bands of gaseous oxygen molecules in the optical cell.

ESR Spectra of Polyethylene Irradiated with Ultraviolet Light

ESR Spectra at $77^{\circ} \mathrm{K}$. Nitrogen-filled samples of both low- and high-density polyethylene gave apparent eight-line spectra (I) as shown in Figures $4 \mathrm{a}$ and $7 \mathrm{a}$ after irradiation in the liquid nitrogen Dewar by a Xe short arc lamp without any filters. The $g$-value of the spectrum was 2.004. However, as described in a previous paper, ${ }^{6}$ an apparent singlet spectrum (II) $(g=2.001$, see Figure 1a in ref 6) was observed when the highly-evacuated sample of low-density polyethylene $\left(10^{-6} \mathrm{mmHg}\right)$ was irradiated under the same conditions, and this difference was ascribed to "pressure effect." The pressure at which the spectrum (II) changes into spectrum (I) was found to be about $10^{-3} \mathrm{mmHg}$. But when a UV-D25 filter which passed UV light of wavelength between 235 and $410 \mathrm{~m} \mu$ was applied, the spectrum (I) was observed irrespective of the pressure in the sample tube. Therefore the appearance of the spectrum (II) might be caused by a rise of temperature as described in the experimental section. This coincides with the fact that the pressure of $10^{-3}$ $\mathrm{mmHg}$ is about where the gas phase becomes thermally conducting. The $g$-value of the spectrum (II) is the same as that of the singlet spectrum which appeared during the warm-up experiment of polyethylene irradiated in nitrogen atmosphere as described later.

The wavelength dependence of radical formation was studied by means of an AT series of filters as shown in Figure 2. ESR spectra of irradiated polyethylene began to appear when the sample was irradiated with UV light of wavelength longer than $280 \mathrm{~m} \mu$ by using a UV31 filter. The sample was irradiated successively with a light of shorter wavelength. The signal intensity of the ESR spectra increased as UV light included the shorter wavelength.

The same spectra (I) were observed from both samples in $\mathrm{N}_{2}$ and in $\mathrm{O}_{2}$ after irradiation at $-196^{\circ} \mathrm{C}$. It is remarkable, however, that the intensity of the ESR spectra of the sample in $\mathrm{O}_{2}$ was greater than that in $\mathrm{N}_{2}$ for all wavelengths studied here as shown in Figure 2.

The dependence of the rate of radical formation on the light intensity is shown in Figure 3. When the intensity is weaker, the rate of radical formation depends on $I^{1}$, although at stronger intensity the dependence is apparently almost 
ESR Study of UV-Irradiated Polyethylene

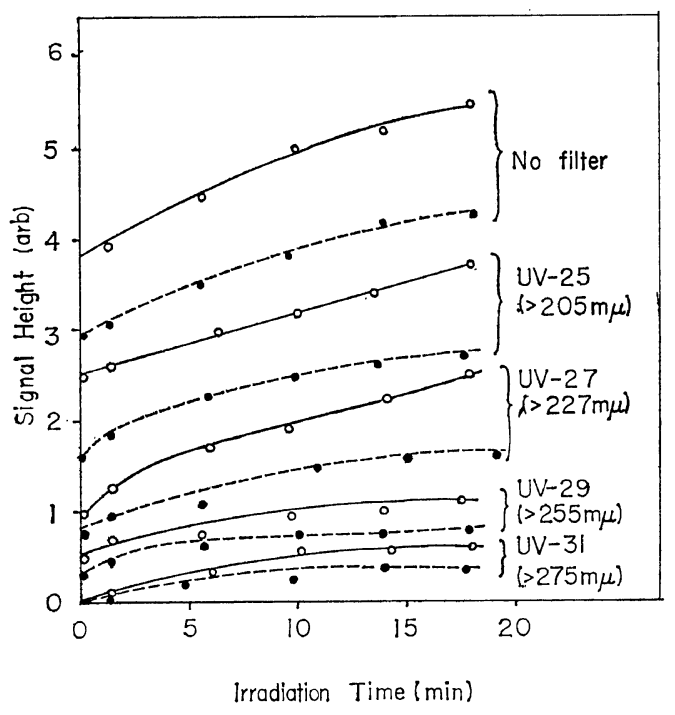

Figure 2. Dependence of ESR signal intensity of free radicals in polyethylene on irradiation time. Irradiations were carried out successively with the light of longer wavelength to that of shorter wavelength by using color glass filters. Solid and dotted lines show signal intensity obtained after irradiation of the sample at $-196^{\circ} \mathrm{C}$ in oxygen and in nitrogen atmosphere, respectively. The signals observed in these experiments were the same irrespective of both atmosphere and irradiation wavelength.
$I^{0.1}$, which might be caused by the limitation of the number of carbonyl groups in the polymer as will be explained in the discussion.

It should be mentioned that the rate of radical formation in polyethylene in $\mathrm{N}_{2}$ decreased with repetitions of irradiation, that is, a smaller rate of radical formation was obtained when the subsequent irradiation at $-196^{\circ} \mathrm{C}$ was carried out on the sample which had been kept at room temperature after the preceding irrradiation at $-196^{\circ} \mathrm{C}$. On the other hand, for the sample in $\mathrm{O}_{2}$, the rate of radical formation did not greatly change but the resolution of the spectrum became poorer at the center.

The change in spectrum intensity was found

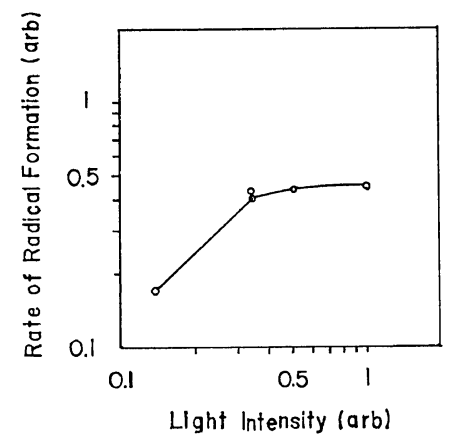

Figure 3. The dependence of the rate of radical formation on the intensity of incident light.
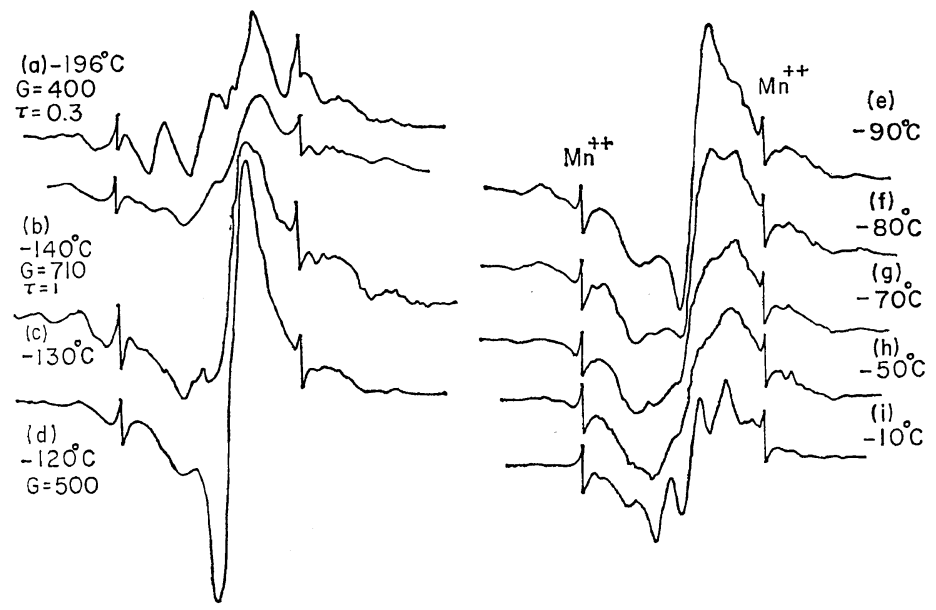

Figure 4. Change of ESR spectrum of low-density polyethylene irradiated with ultraviolet light in nitrogen atmosphere with increasing temperature: irradiation time, $2 \mathrm{hr}$, irradiation temp, at $-196^{\circ} \mathrm{C}$. G represents an amplifier gain setting. The separation between the two $\mathrm{Mn}^{++}$peaks is 86.7 gauss. 


\section{K. Tsuji and T. SEIKI}

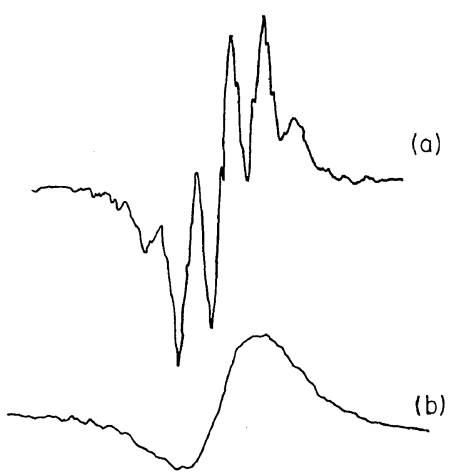

Figure 5. Change of spectral shape of allylic radicals in low-density polyethylene with temperature of ESR measurements: (a) measurement at $40^{\circ} \mathrm{C}$; (b) at $-196^{\circ} \mathrm{C}$.

at the moments of turning on and off the UV light; the intensity increased when the light was cut off and decreased when the light was on. This is thought to be caused by the change in temperature of the sample by irradiation since analogous change was observed when the sample was irradiated with the light of a wavelength longer than $600 \mathrm{~m} \mu$.

Spectrum Change on Warming. Figure 4 shows change of the ESR spectrum observed when the low-density polyethylene sample irradiated in $\mathrm{N}_{2}$ was warmed successively to $-10^{\circ} \mathrm{C}$. At $-140^{\circ} \mathrm{C}$ the eight-line spectrum became poorly resolved, and at about $-130^{\circ} \mathrm{C}$ drastic changes started to give a prominent singlet spectrum at $-120^{\circ} \mathrm{C}$ whose $g$-value was 2.001 . This singlet spectrum gradually decayed out at a higher temperature. At $-10^{\circ} \mathrm{C}$ there remained an apparent five-line spectrum with a separation of about 12 gauss. Upon further warming this spectrum was proved to be a seven-line spectrum with a substructure of separation of about 4 gauss, and the $g$-value was 2.003. This spectrum is due to allylic radicals as described later. This spectrum changed into an apparent singlet spectrum when measured at $-196^{\circ} \mathrm{C}$ as shown in Figure 5. The apparent change in the spectrum shape had already occurred at $-80^{\circ} \mathrm{C}$.

The intensity change during the warm-up experiment is shown in Figure 6. It is clearly seen that the spectral intensity increased over the initial value in the temperature range between -130 and $-80^{\circ} \mathrm{C}$.

The same warm-up experiment was carried out for the high-density polyethylene sample, and the spectrum change was almost similar to that for low-density polyethylene as shown in Figure 7. But the spectrum at lower temperature was better resolved and this made the assignment of the spectrum easier. The spectrum observed at $-196^{\circ} \mathrm{C}$ is an apparent eight-line spectrum with a total width of about 155 gauss and the width of the six-line component is about

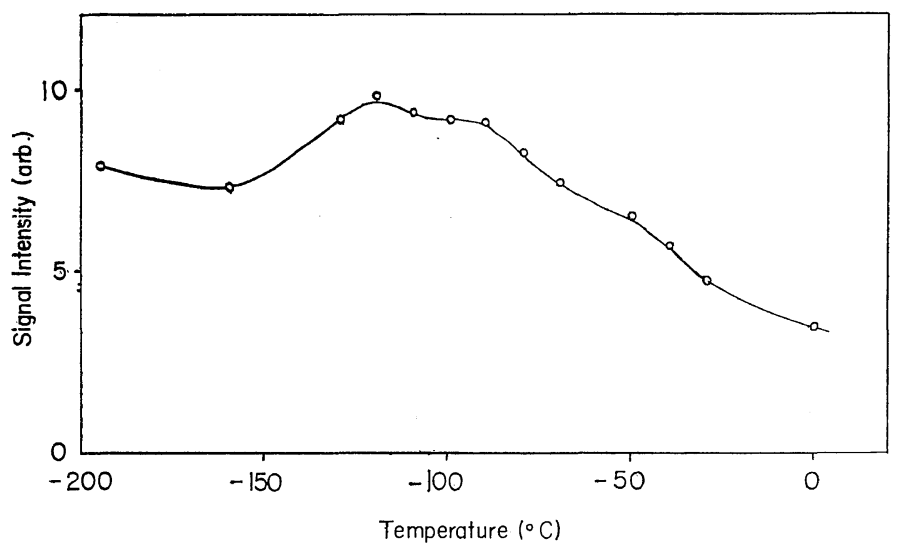

Figure 6. Intensity change of ESR spectrum of irradiated low-density polyethylene in nitrogen atmosphere during the warm-up experiment (see Figure 4). Intensity was not corrected in consideration of change in Boltzmann distribution of electrons since the intensity of allylic radicals did not apparently obey this distribution law. 


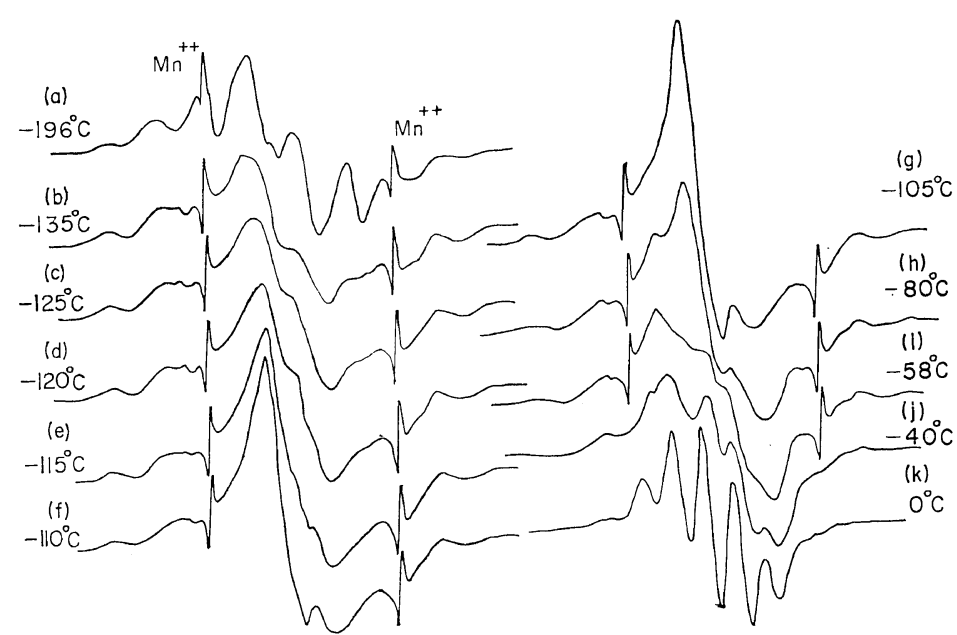

Figure 7. Change of ESR spectrum of high-density polyethylene irradiated with ultraviolet light in nitrogen atmosphere with increasing temperature: irradiation time, $90 \mathrm{~min}$; irradiation temp, at $-196^{\circ} \mathrm{C}$. The separation between the two $\mathrm{Mn}^{++}$peaks is 86.7 gauss.

110 gauss. There was a six-line spectrum observed at about $-125^{\circ} \mathrm{C}$ with a separation of about 30 gauss. According to the comparison of the spectrum at $-196^{\circ} \mathrm{C}$ with that at $-135^{\circ} \mathrm{C}$, it was deduced that the spectrum observed at $-196^{\circ} \mathrm{C}$ consists of two six-line spectra with separations of about 30 gauss and about 22 gauss. The latter six-line spectrum disappeared at a lower temperature. The poor resolution at the center of the six-line spectrum observed at $-135^{\circ} \mathrm{C}$ may indicate the start of the appearance of the singlet spectrum at this temperature.

One of the noticeable points is that the intensity of the singlet observed during the warm-up

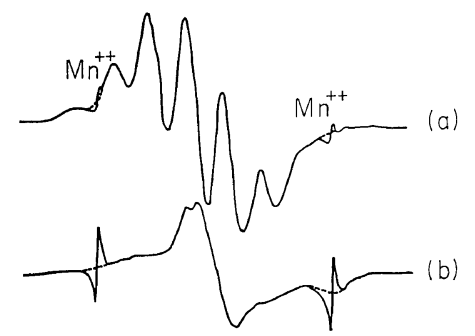

Figure 8. Change of spectral shape of allylic radicals in high-density polyethylene with temperature of ESR measurements: (a) measurement at $0^{\circ} \mathrm{C}$; (b) at $-196^{\circ} \mathrm{C}$. The separation between the two $\mathrm{Mn}^{++}$peaks is 86.7 gauss. process for high-density polyethylene was smaller than that for low-density polyethylene. Another point is the spectral shape of the allylic free radicals measured at lower temperature, which was not a simple singlet spectrum (Figure 8). The signal intensity also increased during the warm up process as shown in Figure 9.

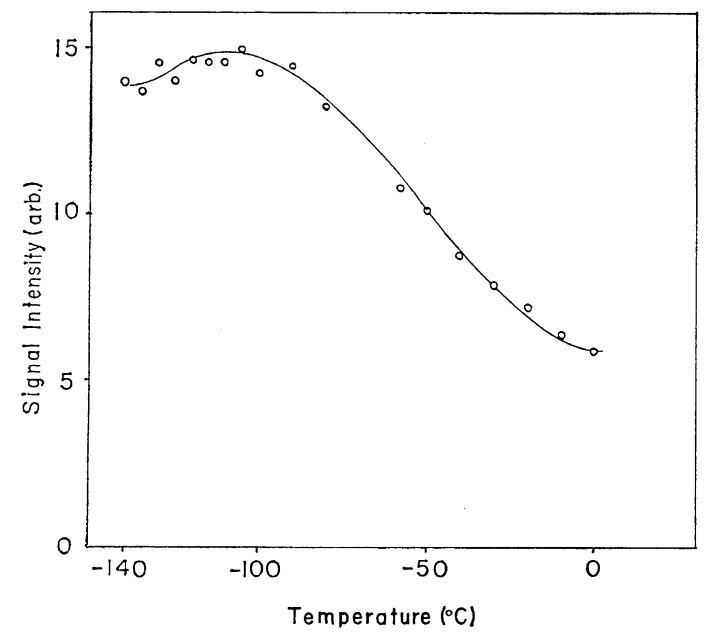

Figure 9. Intensity change of ESR spectrum of irradiated high-density polyethylene in nitrogen atmosphere during the warm-up experiment (see Figure 7). Intensity was not corrected in consideration of change in Boltzmann distribution of electrons. 


\section{K. TsujI and T. Seiki}

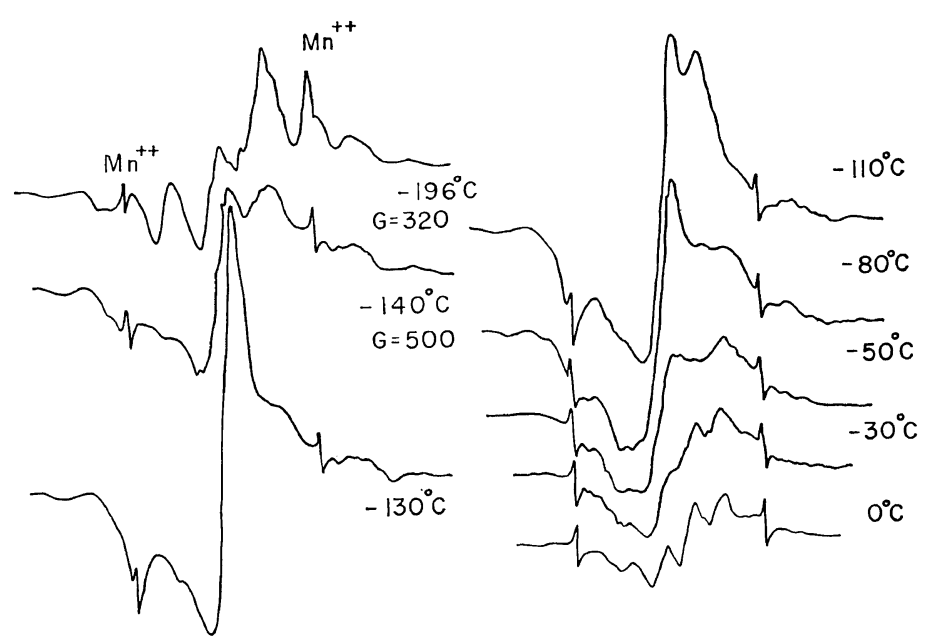

Figure 10. Change of ESR spectrum of low-density polyethylene irradiated with ultraviolet light in an air with increasing temperature: irradiation time, $90 \mathrm{~min}$; irradiation temp, at $-196^{\circ} \mathrm{C}$. G represents an amplifier gain setting. The separation between the two $\mathrm{Mn}^{++}$peaks is 86.7 gauss.

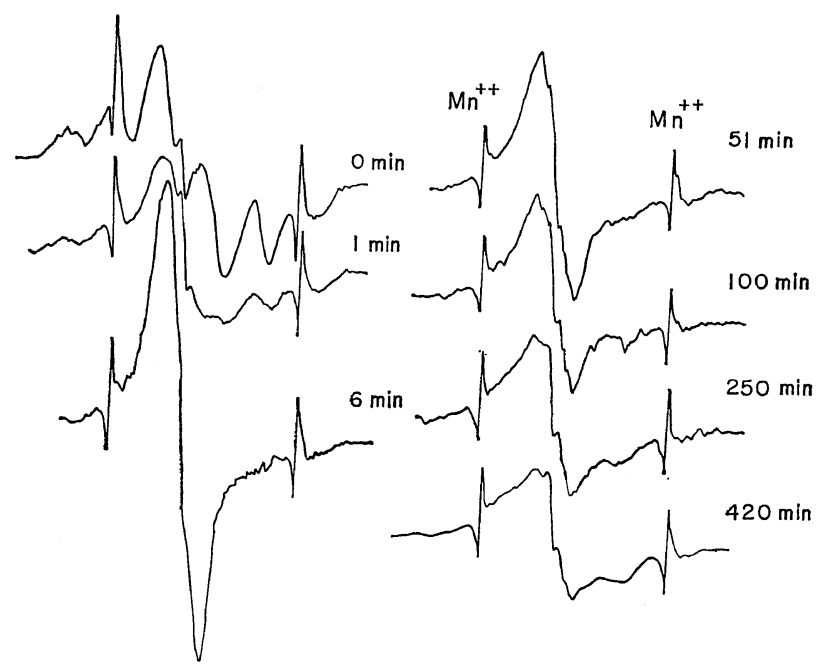

Figure 11. Change of ESR spectrum of low-density polyethylene irradiated with ultraviolet light in nitrogen atmosphere with treatment at $-78^{\circ} \mathrm{C}$. Times written on the right-hand sides of the spectra are times of treatment at $-78^{\circ} \mathrm{C}$. The separation between the two $\mathrm{Mn}^{++}$peaks is 86.7 gauss.

On the other hand, the sample irradiated in air or in $\mathrm{O}_{2}$ gave an asymmetric spectrum characteristic of peroxy radicals when the sample was warmed to $-130^{\circ} \mathrm{C}$, although the same spectrum was observed at $-196^{\circ} \mathrm{C}$ as the sample irradiated in $\mathrm{N}_{2}$ (Figure 10). The $g$-values of the spectrum due to peroxy radicals were $g_{\|}=$
2.032 and $g_{\perp}=2.004$. These values are close to the values for the peroxy radicals reported in the literature. ${ }^{10}$ The formation of peroxy radicals, however, was not complete as some shoulders of the broad six-line spectrum were observed until $-80^{\circ} \mathrm{C}$. Upon successive warming, the intensity of the peroxy radicals decreased 


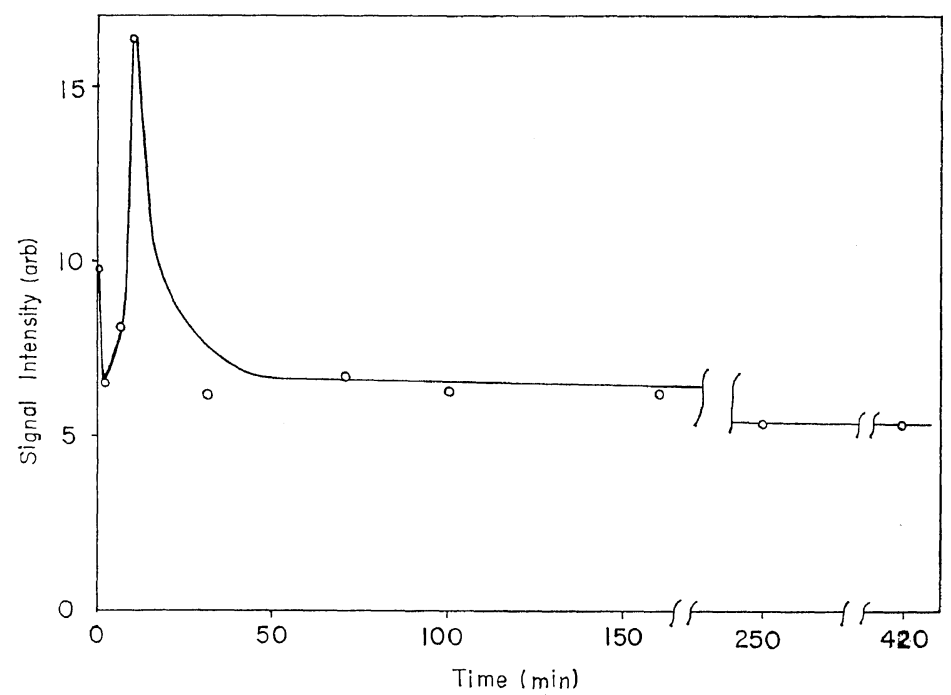

Figure 12. Intensity change of ESR spectrum of low-density polyethylene irradiated in nitrogen atmosphere by treatment at $-78^{\circ} \mathrm{C}$.

gradually, and there remained an apparent fiveline spectrum due to allylic free radicals at $0^{\circ} \mathrm{C}$.

The sample irradiated in vacuo (low-density polyethylene), however, did not give peroxy radicals even when the sample was warmed up in the presence of air from $-196^{\circ} \mathrm{C}$ to room temperature for $5 \mathrm{hr}$. This may reflect the difficulty of diffusion of oxygen molecules into the polymer during the warm-up experiment.

The decay rate of allylic radicals above room temperature was found to be larger in air than in nitrogen atmosphere or in vacuo.

Treatment at $-78^{\circ} \mathrm{C}$. When the low-density polyethylene sample irradiated in $\mathrm{N}_{2}$ at $-196^{\circ} \mathrm{C}$ was treated at $-78^{\circ} \mathrm{C}$, the sharp singlet spectrum appeared at the earlier stage and gradually decayed as shown in Figures 11 and 12 . After long-time treatment at $-78^{\circ} \mathrm{C}$, there was observed a broad spectrum with some shoulders, which could be attributed to allylic radicals since a five-line spectrum with a coupling constant of about 12 gauss was obtained when measured at room temperature. In this case an increase of signal intensity was also observed. Analogous behavior was observed for the highly-evacuated sample by subsequent irradiation at $-196^{\circ} \mathrm{C}$, when the sample was kept at room temperature after the first irradiation.
The sample in $\mathrm{O}_{2}$ or in air, on the other hand, gave peroxy radicals after treatment at $-78^{\circ} \mathrm{C}$ as shown in Figure 13, and was stable

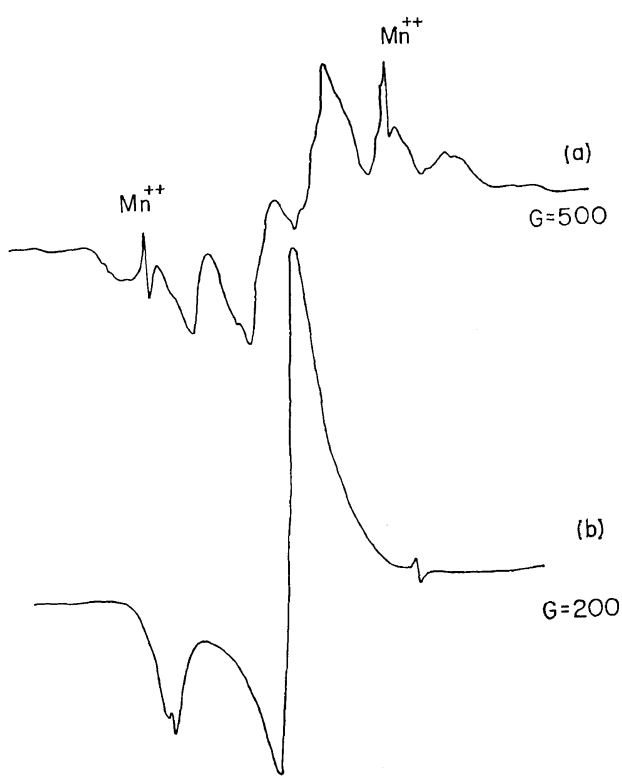

Figure 13. Change of ESR spectrum of low-density polyethylene irradiated with ultraviolet light in an air for $70 \mathrm{~min}$ at $-196^{\circ} \mathrm{C}$ with treatment at $-78^{\circ} \mathrm{C}$ for $2 \mathrm{~min}$. $\mathrm{G}$ represents an amplifier gain setting. The separation between the two $\mathrm{Mn}^{++}$ peaks is 86.7 gauss. 


\section{K. TsujI and T. SeIKI}

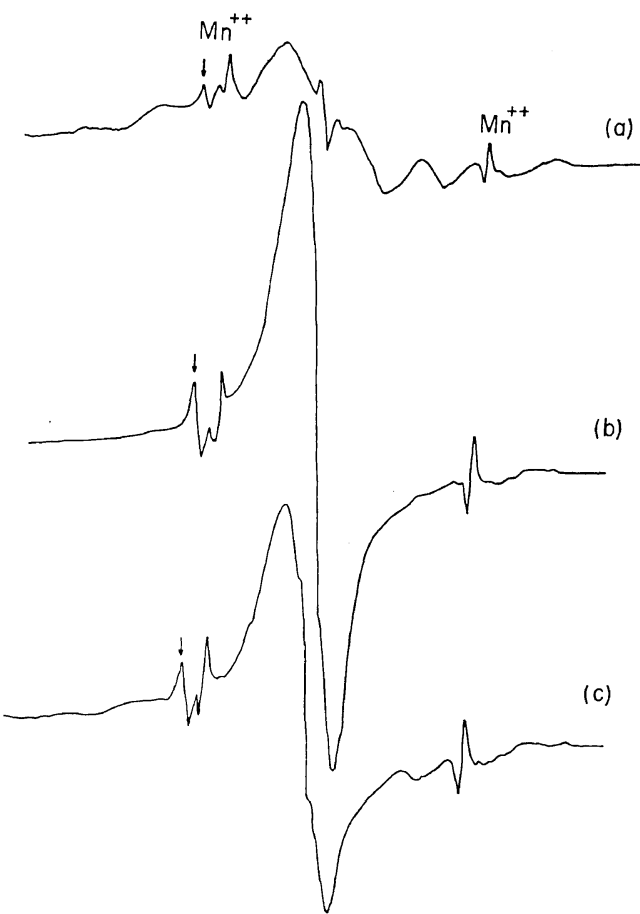

Figure 14. ESR spectra of irradiated low-density polyethylene: (a) after irradiation with ultraviolet light for $25 \mathrm{~min}$; (b) after treatment of (a) at $-78^{\circ} \mathrm{C}$ for $1 \mathrm{~min}$; (c) after irradiation of (b) with the light of wavelength longer than $360 \mathrm{~m} \mu$ (UV-39 filter) for $57 \mathrm{~min}$. Almost the same spectrum as (b) was obtained after subsequent treatment of (c) at $-78^{\circ} \mathrm{C}$ for $1 \mathrm{~min}$. Arrow marks represent the signal induced in the sample tube.

at this temperature. But the signal intensity of peroxy radicals was larger than that of the initial alkyl radicals.

On the other hand, the sample irradiated in vacuo did not give peroxy radicals even after the sample was treated at $-78^{\circ} \mathrm{C}$ for an hour in the presence of air. The ESR spectrum of the peroxy radicals, however, appeared after keeping the sample at $-78^{\circ} \mathrm{C}$ overnight. This is thought to be caused by slow diffusion of oxygen molecules into the polymer at $-78^{\circ} \mathrm{C}$.

The sample irradiated after evacuation to $10^{-5} \mathrm{mmHg}$ at $-196^{\circ} \mathrm{C}$ gave peroxy radicals on subsequent treatment at $-78^{\circ} \mathrm{C}$ for $1 \mathrm{~min}$. This fact indicates that the free radicals reacted with oxygen molecules occluded in the polymer. From these results it can be deduced that free

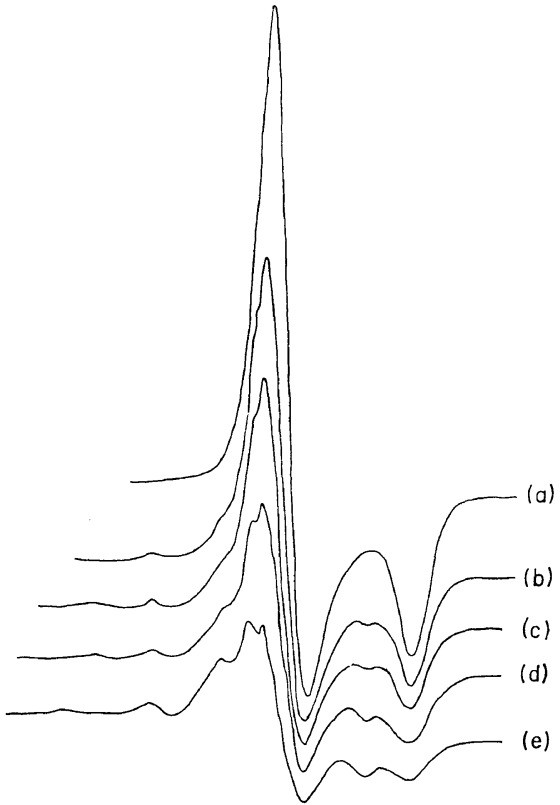

Figure 15. Photo-induced conversion of peroxy radicals in high-density polyethylene irradiated in oxygen atmosphere: (a) peroxy radicals were produced by treatment of the irradiated sample at $-78^{\circ} \mathrm{C}$ for $1 \mathrm{~min}$; (b) after irradiation of ultraviolet light of the wavelength longer than $280 \mathrm{~m} \mu$ for $4 \mathrm{~min}$; (c) for $9 \mathrm{~min}$; (d) for $19 \mathrm{~min}$, and (e) for $39 \mathrm{~min}$.

radicals were produced within the polymer matrix, probably in an amorphous region mainly, and not on the polymer surface.

High-density polyethylene showed similar spectral change as low-density polyethylene.

Photoinduced Radical Conversions. The sharp singlet spectrum obtained after treating the sample in $\mathrm{N}_{2}$ or in vacuo at $-78^{\circ} \mathrm{C}$ converted in some extent to a spectrum similar to that observed initially at $-196^{\circ} \mathrm{C}$, after it was irradiated with UV-light without application of any filters. Analogous conversion was also observed when it was irradiated with the light of a wavelength longer than $360 \mathrm{~m} \mu$ (UV-39 filter), but to a smaller extent as shown in Figure 14. The converted spectrum was again changed into a sharp singlet spectrum by subsequent treatment at $-78^{\circ} \mathrm{C}$.

The peroxy radicals decayed and the same spectrum as observed initially at $-196^{\circ} \mathrm{C}$ appeared after subsequent irradiation with UV- 
light without any filters. The light of a wavelength longer than $280 \mathrm{~m} \mu$ could cause a similar change as shown in Figure 15 but only to a small extent. The light of a wavelength longer than $300 \mathrm{~m} \mu$ also caused the same change but at a much smaller rate.

The allylic radicals were irradiated at $-196^{\circ} \mathrm{C}$ by UV-light with application of a UV-39 filter. But the spectrum did not change after irradiation for an hour.*

\section{DISCUSSION}

\section{Absorption of Energy of Light}

Although several studies have been reported on ESR spectra of alkane polymers irradiated with UV-light, the fundamental processes of radical formation are not completely clarified in spite of thier importance.

If polyethylene is composed of only $-\mathrm{CH}_{2}-$ bonds, the light of wavelengths longer than 160 $\mathrm{m} \mu$ cannot be absorbed and the ultraviolet ragion must be transparent. As described in the results section, commercial polyethylene shows some absorptions in the UV-region; one is the apparent absorption due to surface and Rayleigh scattering and the other is due to some irregular groups incorporated in the polymer during manufacture and processing or autooxidation. The former cannot contribute to actual absorption of light energy. Rảnby, et al., ${ }^{3}$ however, claim that the ultraviolet light is causing breakages of $\mathrm{C}-\mathrm{C}$ and $\mathrm{C}-\mathrm{H}$ bonds in the polymer as primary effects from the view points that the ultraviolet light has enough energy to break these chemical bonds and that the polymer film has non-100\% transmittance of UV-light. On the other hand, Burgess ${ }^{17}$ has suggested that the chemical effect of ultraviolet irradiation on polyethylene and polypropylene may be due to carbonyl groups or double bonds at the chain ends which absorb ultraviolet light. Charlesby, et al., ${ }^{2}$ have also reported that absorbers of ultraviolet light are carbonyl groups as irregular bonds. They proposed two possible mechanisms to produce alkyl free radicals by

* When a super-high pressure mercury lamp was applied as a light source, some spectrum due to alkyl radicals appeared after longer time of irradiation. The intensity, however, was quite small. the energy absorbed by carbonyl groups as follows (a) a transfer of energy from the doubly excited carbonyl groups, causing ionization in the chain or the breakage of the $\mathrm{C}-\mathrm{H}$ bond in a neighbouring methylene group, (b) hydrogen atom abstraction from a methylene group by an adjacent excited carbonyl group. They concluded that the latter mechanism was the more likely. According to this mechanism, however, the following reactions are assumed.

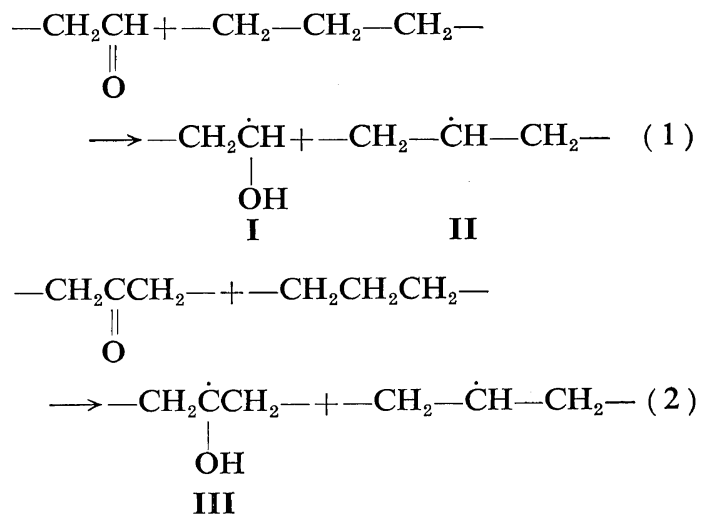

The alcohol radical I could be expected to decompose by ultraviolet light as follows according to the study on photo-induced radical conversions of ethanol radicals. ${ }^{18}$

$$
\begin{gathered}
-\mathrm{CH}_{2} \dot{\mathrm{C}} \mathrm{H} \stackrel{h \nu}{\longrightarrow}-\mathrm{CH}_{2} \mathrm{CH}+\mathrm{H} . \\
\mathrm{H} \cdot+-\mathrm{CH}_{2}-\mathrm{CH}_{2}-\mathrm{CH}_{2}- \\
\longrightarrow-\mathrm{CH}_{2}-\dot{\mathrm{C}} \mathrm{H}-\mathrm{CH}_{2}-+\mathrm{H}_{2}
\end{gathered}
$$

The radical III, on the other hand, would not be photolized since the $\left(\mathrm{CH}_{3}\right)_{2} \mathrm{COH}$ radical is not sensitive to UV-light. ${ }^{18}$ As will be described in the next section, the ESR spectrum observed in the present investigation cannot be explained by this mechanism. Moreover Winslow, et al. ${ }^{19}$ have also suggested that this mechanism does not seem to contribute significantly to polyethylene degradation.

Another presumable mechanism is energy transfer from unremovable impurities which absorb light energy. The same kind of mechanism was reported for a silicone-naphthalene system ${ }^{20}$ where the energy of naphthalene excited by a two-photon process was transfered to the 
polymer to produce free radicals. However, in the present investigation, linear dependence of the rate of radical formation on light intensity tends to exclude this possibility.

It is recently reported ${ }^{21,22}$ that photochemical reactions of copolymers of ethylene and carbon monoxide as model compounds of polyethylene, are those occurring in simple dialkyl ketones. In fact, dialkyl ketones of low molecular weight gave a similar ESR spectrum to that of polyethylene after UV-irradiation at $-196^{\circ} \mathrm{C}$. Wavelength dependence of radical formation also supports the theory that ketonic carbonyl groups are responsible for radical formation in polyethylene. Formation of carbon monoxide was reported after UV-irradiation of polyethylene. $^{23,24}$ Therefore the Norrish-type I reaction of carbonyl groups seems to be a primary reaction for radical formation when polyethylene is irradiated with UV-light at $-196^{\circ} \mathrm{C}$, although the Norrish-type II reaction is also important for polymer degradation. ${ }^{25}$ The observation of acyl radicals, as will be described later, shows validity of this mechanism, and according to the Norrish-type I reaction, ESR spectra observed after UV-irradiation can be explained reasonably as described in the next section.

In the presence of oxygen, charge-transfer complexes of polyethylene with oxygen molecules may be another UV-absorber. The difference of the absorption spectra of polyethylene films in $\mathrm{O}_{2}$ and in $\mathrm{N}_{2}$ clearly shows the presence of the complex. Greater radical yield in $\mathrm{O}_{2}$ and the identity of the ESR spectra in $\mathrm{N}_{2}$ and in $\mathrm{O}_{2}$ may indicate the presumable participation of the charge-transfer complexes in the fundamental process of radical formation, that is, absorption of energy of light. ${ }^{9}$ It is plausible to suppose that the energy absorbed by the charge-transfer complexes is to be transferred to carbonyl groups. Detailed discussion of this point will be published elsewhere. ${ }^{26}$

\section{Identification of Free Radicals}

Spectrum Observed Immediately after Irradiation at $-196^{\circ} \mathrm{C}$. Primarily ESR spectrum of polyethylene was thought to be a six-line spectrum and free radicals responsible for it have been identified as alkyl radicals of the type $-\mathrm{CH}_{2}$ $-\dot{\mathrm{C}} \mathrm{H}-\mathrm{CH}_{2}-{ }^{2-6,8}$ which were the same type of free radicals as also produced by $\gamma$-irradiation. Rånby, et al., ${ }^{3}$ claimed the existence of a fiveline spectrum due to the free radicals $-\mathrm{CH}_{2} \mathrm{CH}_{2}$. but this interpretation is not conclusive. ${ }^{5} \mathrm{Re}$ cently we pointed out that two more lines were observed on both sides of the six-line spectrum ${ }^{6}$ and the presence of the free radicals of the type $-\mathrm{CH}_{2}-\underset{\mathrm{C}}{\dot{\mathrm{C}}-\mathrm{CH}_{3}}-\mathrm{CH}_{2}-$ was proposed. However as described in the results section, the ESR spectrum observed at $-196^{\circ} \mathrm{C}$ can be thought to be composed of two six-line spectra with separations of about 30 and 22 gauss, and the total widths of the two spectra are about 155 and 110 gauss, respectively. These spectra can be attributed reasonably to free radicals $-\mathrm{CH}_{2}-\dot{\mathrm{C}} \mathrm{H}-$ $\mathrm{CH}_{2}-$ and $-\mathrm{CH}_{2}-\mathrm{CH}_{2} \cdot$. The latter radicals are those also produced by mechanical destruction of polymers. ${ }^{27}$ For the free radical $-\mathrm{CH}_{2}$ $-\mathrm{CH}_{2} \cdot, a_{\mathrm{H} \alpha}$ is 22 gauss and $a_{\mathrm{H} \beta}$ are 53 and 18 gauss, and these values result in an apparent six-line spectrum of the total width of about 115 gauss, which almost agrees with our value. The free radical $-\mathrm{CH}_{2}-\dot{\mathrm{C}} \mathrm{H}-\mathrm{CH}_{2}-$ shows the six-line spectrum with the total width of about 162 gauss.

Since an apparent spectrum observed immediately after irradiation at $-196^{\circ} \mathrm{C}$ was an eight-line spectrum, it may be assigned simply to free radicals $-\mathrm{CH}_{2}-\dot{\mathrm{C}} \mathrm{H}-\mathrm{CH}_{3}$ which are known to give a similar eight-line spectrum. ${ }^{28}$ This identification, however, can be excluded by the fact that UV-irradiation will induce the following conversion even though the free radicals $-\mathrm{CH}_{2}-\dot{\mathrm{C}} \mathrm{H}-\mathrm{CH}_{3}$ are produced.

$$
-\mathrm{CH}_{2}-\dot{\mathrm{C}} \mathrm{H}-\mathrm{CH}_{3} \stackrel{h_{\nu}}{\longrightarrow}-\mathrm{CH}_{2}-\mathrm{CH}_{2}-\mathrm{CH}_{2} \text {. }
$$

This radical conversion was found for butyl radicals. ${ }^{29}$

Singlet Specrum Observed after Heat-Treatment. The sharp singlet observed at about $-120^{\circ} \mathrm{C}$ during the warm-up experiment and by treatment at $-78^{\circ} \mathrm{C}$ for a short time was first identified as polyenyl radicals. ${ }^{3}$ Observed instability, however, is not expected for radicals of this kind. Recently Hama, et al., ${ }^{7}$ observed a similar sharp singlet spectrum after warming the sample to $-110^{\circ} \mathrm{C}$. They attributed it to 
free radicals $-\mathrm{CH}_{2}-\underset{\mathrm{O}}{\mathrm{C}} \cdot$. Noda, et al.,${ }^{30}$ reported

that this type of free radical gives an apparent singlet spectrum. But some hyperfine structure might be expected from the fact that acetyl radicals show a hyperfine structure with a separation of 5-6 gauss. ${ }^{31-33}$ The $g$-value (2.001), however, is very close to the average of $g$ values of acyl radicals from malonic acid ${ }^{33}$ and of formyl radicals. ${ }^{34}$ Therefore it seems correct that the sharp singlet spectrum observed here is due to some kind of acyl radical. But as will be described in the next section, a more probable structure of the acyl radical is $-\mathrm{CH}_{2}$ $\dot{\mathrm{C}}=\mathrm{O}$

$-\stackrel{\mathrm{C}}{\mathrm{H}}-\mathrm{CH}_{2}-$, which shows a similar singlet spectrum to that observed in the present investigation.

Seven-Line Spectrum Observed Near Room Temperature. The seven-line spectrum with a coupling constant of about 12 gauss observed near room temperature can be attributed to allylic free radicals $-\mathrm{CH}_{2}-\dot{\mathrm{C}}^{1} \mathrm{H}-\mathrm{C}^{2} \mathrm{H}=\mathrm{C}^{3} \mathrm{H}$ $-\mathrm{CH}_{2}$ - The spin density of the allylic radical is known to be $\rho_{1}=\rho_{3}=+0.622$ and $\rho_{2}=-0.235$. $^{35}$ Therefore the expected coupling constants are $23 \times 0.622=14$ gauss and $23 \times 0.231=5$ gauss which show close agreement with the present experimental values.

Formation Mechanism and Behavior of Free Radicals

Alkyl Radicals. The primary reaction in polyethylene irradiated with UV-light at $-196^{\circ} \mathrm{C}$ would be the Norrish-type I reaction as described before.*

* The direct decomposition of the carbonyl groups at the chain ends may also be expected as follows.<smiles>CCC(C=O)CCC=O</smiles>

Formyl radicals $(\cdot \mathrm{CHO})$ are known to decay by irradiation of light of $500-600 \mathrm{~m} \mu{ }^{18}$ In the present investigation, however, no formyl radicals were observed even when polyethylene was irradiated by using a UV-D25 filter which cuts the light of 500$600 \mathrm{~m} \mu$. Therefore the direct decomposition of the carbonyl groups at the chain ends would be negligible here.

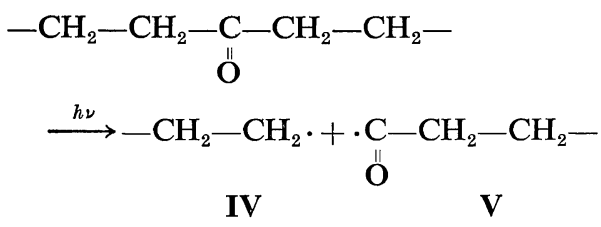

Linear dependence of the rate of radical formation on the light intensity indicates that excitation of carbonyl groups is one photonic process in this case. The free radical $\mathbf{V}$ is known to remove $\mathrm{CO}$ by irradiation with visible light. $^{30}$ This reaction might also proceed by UV-irradiation, since no acyl radicals were observed even when the irradiation was carried out by applying the UV-D25 filter.

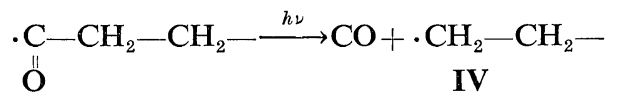

Reactions 5 and 6, however, may be instantaneous since no evidence was obtained for the presence of the free radical $\mathbf{V}$ immediately after irradiation. Moreover, it is known that reaction 6 can proceed with the excess energy carried off by the acyl radicals. ${ }^{36}$ This mechanism is consistent with the observation of the linear dependence of the rate of radical formation on the light intensity. ${ }^{* *}$

** When the light intensity is stronger, the dependence of the rate of radical formation on the light intensity is smaller than 1 . This observation can be explained as follows.

The photolysis of the carbonyl groups gives two free radicals according to the Norrish-type I reaction, and the following equations are obtained.

$$
\begin{gathered}
\mathrm{C} \stackrel{h \nu}{\longrightarrow} 2 \mathrm{R} . \\
\mathrm{d}[\mathrm{C}] / \mathrm{d} t=-k I[\mathrm{C}] \\
\mathrm{d}[\mathrm{R} \cdot] / \mathrm{d} t=2 k I[\mathrm{C}]
\end{gathered}
$$

where $[C]$ and $[R \cdot]$ are concentrations of the carbonyl groups and free radicals in the polymer, and $I$ and $k$ are the light intensity and the rate constant, respectively. From these equations, the rate of radical formation can be expressed by eq 3 .

$$
\mathrm{d}[\mathrm{R} \cdot] / \mathrm{d} t=2[\mathrm{C}]_{0} k I \exp (-k I t)
$$

Therefore the initial rate of radical formation $(t \doteqdot 0)$ is proportional to $I^{1}$. But when the light intensity becomes stronger, the exponential term cannot be ignored and the apparent dependence on $I$ will be smaller than 1 . 
The end radical IV has considerable reactivity and it is reported ${ }^{37}$ that the reaction of terminal radicals of polyethylene with a neighbouring chain occurs at a measurable rate at $140^{\circ} \mathrm{K}$ and has an activation energy of only $4 \pm 1 \mathrm{kcal} \mathrm{mol}^{-1}$.

$$
\begin{gathered}
-\mathrm{CH}_{2}-\mathrm{CH}_{2} \cdot+-\mathrm{CH}_{2}-\mathrm{CH}_{2}-\mathrm{CH}_{2}- \\
\stackrel{{ }_{4}}{\longrightarrow}-\mathrm{CH}_{2}-\mathrm{CH}_{3}+-\mathrm{CH}_{2}-\dot{\mathrm{C}} \mathrm{H}-\mathrm{CH}_{2}- \\
\text { VI }
\end{gathered}
$$

Therefore this reaction proceeded to some extent during irradiation when the temperature of the sample rose somewhat above $-196^{\circ} \mathrm{C}$. But it is known that mechanical destruction of polyethylene at $-196^{\circ} \mathrm{C}$ produces free radicals IV which are stable for over several hours. ${ }^{38}$ This means that the free radicals IV produced by mechanical destruction cannot abstract hydrogen atoms within several hours at $-196^{\circ} \mathrm{C}$. However UV-irradiation of polyethylene in liquid nitrogen (without a tube) for $30 \mathrm{~min}$ caused the appearance of the same ESR spectrum as shown in Figure $7 \mathrm{a}$ which consisted of spectra due to the free radicals IV and VI. From these facts it is supposed that the free radicals IV produced by UV-irradiation have extra energy enough to abstract hydrogen atoms from neighboring bonds even at $-196^{\circ} \mathrm{C}$. Therefore the free radicals IV can be considered to be in some excited state $-\mathrm{CH}_{2}-\mathrm{CH}_{2}$. ${ }^{*}$ immediately after their formation with ultraviolet irradiation.

On further warming, the six-line spectrum due to the free radical IV decayed according to the reaction (7), and the intensity of the six-line spectrum due to the free racical VI increased, to some extent. The poor resolution at the center of the spectrum would indicate the appearance of the singlet spectrum at this temperature as mentioned in the results section.

The increase of total signal intensity was observed between -140 and $-110^{\circ} \mathrm{C}$. $^{*}$ This phenomenon is specific for UV-irradiated polyethylene, and the sample irradiated with ionizing radiation showed a simple decrease of signal intensity when the sample was warmed up. The

* When the micowave power was attenuated to about $0.1 \mathrm{~mW}$, the apparent incease of signal intensity was not clear. Therefore this phenomenon might have some relation with power saturation. reaction 7 is thought to be responsible for this. Since the free radical IV is very reactive and the reactions are favorable, the product $-\mathrm{CH}_{2}$ $-\mathrm{CH}_{3}$ may have extra energy, that is, excited state $-\mathrm{CH}_{2}-\mathrm{CH}_{3}{ }^{*}$. If this assumption is allowed, one possibility to explain the increase of signal intensity could be supposed as follows

$$
\begin{array}{r}
\mathrm{A} \cdot+\mathrm{RH} \longrightarrow(\mathrm{AH})^{*}+\mathrm{R} . \\
\mathrm{AH}
\end{array}
$$

A. and $\mathrm{H}$. produced from $(\mathrm{AH})^{*}$ would again abstract hydrogen atoms from other parts of the polymer as is shown in eq 7 . The same mechanism has been proposed for the case of irradiated glutathion $^{39}$ in order to explain the increase of $\mathrm{S}$ radicals.

Analogous phenomena of radical increase during the warm-up process have been reported for $\gamma$-irradiated trioxane ${ }^{40}$ and $\gamma$-irradiated sulfone $e^{41}$ and were explained as due to radical formation by recombination of cations and electrons. This mechanism, however, cannot be applicable to the present photoreaction.

Acyl Radicals. When the sample was warmed to $-115^{\circ} \mathrm{C}$, a singlet spectrum appeared due to $\dot{\mathrm{C}}=\mathrm{O}$

to $-\mathrm{CH}_{2}-\mathrm{C} H-\mathrm{CH}_{2}-$ free radicals. The formation of this free radical is caused mainly by the reaction of the alkyl radicals VI and carbon monoxide.

$$
\begin{array}{ccc}
-\mathrm{CH}_{2}-\dot{\mathrm{C}} \mathrm{H}-\mathrm{CH}_{2}-+\mathrm{CO} & \\
\text { VI } & \dot{\mathrm{C}}=\mathrm{O} \\
& \longrightarrow-\mathrm{CH}_{2}-\stackrel{\dot{\mathrm{C}} \mathrm{H}}{ }-\mathrm{CH}_{2}-
\end{array}
$$

This reaction was confirmed by the following experiment. Low-density polyethylene was irradiated with electron beams at $-196^{\circ} \mathrm{C}$ in the presence of carbon monoxide. The six-line spectrum due to the free radicals VI was observed at $-196^{\circ} \mathrm{C}$ after irradiation. When this sample was treated at $-78^{\circ} \mathrm{C}$ for $1 \mathrm{~min}$, the spectrum changed into a singlet spectrum ( $g=$ 2.001) which is quite the same as in the case of UV-irradiation, while the spectrum hardly changed without carbon monoxide after the same treatment. These results will be published in detail elsewhere. ${ }^{42}$ From this experiment, it is confirmed that carbon monoxide is evolved 
in the polymer after UV-irradiation at $-196^{\circ} \mathrm{C}$. Therefore this is direct evidence showing that the Norrish-type I reaction takes place after $\mathrm{UV}$-irradiation of polyethylene at $-196^{\circ} \mathrm{C}$.

The reaction 8 can be thought to proceed by diffusion of carbon monoxide molecules in the polymer at the temperature near $T_{\mathrm{g}}$ of polyethylene $\left(-125^{\circ} \mathrm{C}\right) .^{43}$ The intensity of the sharp singlet spectrum was smaller for high-density polyethylene. This may reflect the fact that an amorphous region is smaller in high-density polyethylene than in low-density polyethylene, where carbon monoxide molecules can diffuse readily and that carbon monoxide molecules cannot react so easily with free radicals in the crystalline region due to slower diffusion.

When the temperature of the sample was raised to over $-100^{\circ} \mathrm{C}$, the intensity of the sharp singlet and the six-line spectrum due to radical VI decreased and there remained the ESR spectrum due to allylic free radicals. The decay of the singlet may be caused by the reaction 9 initiated thermally.

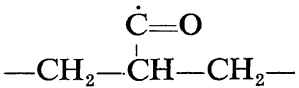

$$
\begin{aligned}
& \longrightarrow-\mathrm{CH}_{2}-\dot{\mathrm{C}} \mathrm{H}-\mathrm{CH}_{2}-+\mathrm{CO} \\
& \text { VI }
\end{aligned}
$$

Allylic Radicals. At the higher temperature, the free radicals VI thus produced by the reaction 9 recombine with each other or abstract hydrogen atoms from other parts of the polymer, and the latter can recycle. When hydrogen atom abstraction takes place from the allylic position of the double bond, allylic radicals are produced and only these radicals are stable at this temperature. Therefore the ESR spectrum due to allklic radicals was only observed at temperatures higher than $-30^{\circ} \mathrm{C}$. The conversion of alkyl radicals produced by irradiation with electron beams to allylic radicals was supposed $^{44,45}$ and studied kinetically. ${ }^{46}$

Allylic radicals showed a well-resolved sevenline spectrum above $0^{\circ} \mathrm{C}$ as indicated in Figures 4 and 8 . These spectra, however, changed into apparent singlet spectra as shown in Figure 4 for low-density polyethylene and into a spectrum with some shoulders as shown in Figure 8 for high-density polyethylene. The ESR spectrum due to the allylic radicals produced by ionizing radiation also changes with temperature of measurements. This was explained by the assumption that methylene groups rotating freely at room temperature hold a certain position at low-temperature. ${ }^{47}$ The reported spectra of polyethylene irradiated with ionizing radiation at $-196^{\circ} \mathrm{C}$, however, was quite different from that observed for the UV-irradiated polyethylene in the present investigation. Since the comparison of the ESR spectra of low- and highdensity polyethylene may lead to the conclusion that the change of the spectra due to the allylic radicals depends on the crystallinity, the allylic radicals could be assumed to be trapped in different regions according to the method of formation, that is UV-irradiation or high energy radiation. $^{8}$ The same conclusion can be drawn from the different behavior in peroxy radical formation. ${ }^{42}$ In the case of high-energy radiation, free radicals are thought to be trapped mainly in crystalline regions ${ }^{48}$ or in regions responsible for $\gamma$-dispersion of polyethylene. ${ }^{49}$ On the other hand, free radicals might be trapped mainly in amorphous regions after ultraviolet irradiation, as mentioned in the results section, where molecules orient at random and a relatively broad signal will result when the rotation of methylene groups is restricted at low temperature. This agrees with the present results.

Long-time treatment at $-78^{\circ} \mathrm{C}$ of low-density polyethylene irradiated at $-196^{\circ} \mathrm{C}$ caused the formation of allylic radicals. The spectrum measured at $-196^{\circ} \mathrm{C}$, however, was not a simple singlet spectrum but had some shoulders, showing that the allylic radicals in this case were trapped in a region different from that for allylic radicals produced after the warm-up to room temperature, perhaps in a region with larger crystallinity. From this result it is supposed that the hydrogen atom abstraction reaction may take place in a different region depending on the temperature or that the crystal morphology was different for these two samples owing to a change in morphology caused by the heat-treatment.

Peroxy Radicals. The clear ESR spectrum due to peroxy radicals was observed when the sample irradiated in air was warmed to about $-130^{\circ} \mathrm{C}$. Therefore it seems plausible that 
precursors of peroxy radicals are mainly the free radical VI.

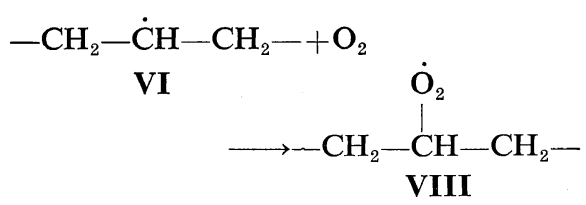

It is likely that this reaction takes place by diffusion of oxygen molecules near the glass transition temperature of polyethylene $e^{43}$ as in the case of acyl radical formation.

The appearance of allylic radicals at higher temperature after peroxy radicals decayed out is thought to be caused by hydrogen atom abstraction by these peroxy radicals as has already been reported..$^{50-53}$ The same type of free radicals as VI would be formed by hydrogen atom abstraction. These free radicals, however, are unstable at higher temperature and abstract hydrogen atoms again or decay by recombination as mentioned above. When hydrogen atom abstractions takes place from allylic positions of double bonds in the polymer, relatively stable allylic free radicals are produced, which were observed. Allylic radicals are also reported to form peroxy radicals, ${ }^{.4}$ and this was confirmed by keeping the sample containing allylic radicals at $-78^{\circ} \mathrm{C}$ in air overnight. But at higher temperatures than $0^{\circ} \mathrm{C}$, allylic free radicals were more stable than peroxy radicals. Therefore, only the ESR spectrum due to allylic radicals was obtained. The decay rate of allylic radicals in the presence of air at higher temperature was found to be greater than that in vacuo. This could be attributed to the contribution of peroxy radicals from allylic radicals to hydrogen atom abstruction or recombination reaction. The same argument has been made ${ }^{55}$ for the decay of alkyl radicals in poly(oxymethylene) and verified. ${ }^{56}$

Effect of Repeated Irradiation. The rate of radical formation in polyethylene in $\mathrm{N}_{2}$ decreased when repeated irradiation was made. This observation can be expected readily according to the mechanism of radical formation described above, that is, the number of dialkyl carbonyl groups decreased by irradiation and chromophores for the subsequent irradiation were small in number compared with the preceding irradi- ation. In the case of irradiation in $\mathrm{O}_{2}$, the resolution of the spectrum became poorer without significant decrease of the rate of radical formation. This can be ascribed to the contribution of photolized species of some photooxidation products such as hydroperoxides produced through hydrogen abstraction by peroxy radicals.

\section{Photoinduced Radical Conversion}

Peroxy Radicals. The peroxy radicals were photolized by ultraviolet light and alkyl radicals were produced. In this case, the energy of light was absorbed by peroxy radicals themselves which are known to have absorption maximum near $250 \mathrm{~m} \mu .^{57}$ Reactions responsible for this change could be written as follows

$$
\begin{aligned}
& \stackrel{\dot{\mathrm{O}}_{2}}{2} \\
&-\mathrm{CH}_{2}- \stackrel{\mathrm{C}}{\mathrm{C}}-\mathrm{CH}_{2} \\
& \stackrel{\mathrm{CH}_{\nu}}{\longrightarrow}--\mathrm{CH}_{2}-\mathrm{CH}_{2} \cdot+\mathrm{M} \text { (other non- } \\
& \text { paramagnetic products) }
\end{aligned}
$$

And some $-\mathrm{CH}_{2}-\mathrm{CH}_{2}$. radicals would produce $-\mathrm{CH}_{2}-\dot{\mathrm{C}} \mathrm{H}-\mathrm{CH}_{2}-$ radicals by hydrogen atom abstraction. The reaction 11 has been postulated for peroxy radicals produced in polytetrafluoroethylene irradiated with ionizing radiation. ${ }^{58-60}$

Acyl Radicals. The sharp singlet spectrum

$$
\dot{\mathrm{C}}=\mathrm{O}
$$

due to acyl radicals $-\mathrm{CH}_{2}-\mathrm{CH}-\mathrm{CH}_{2}-$ changed into a similar spectrum to that observed immediately after the first UV-irradiation of polyethylene at $-196^{\circ} \mathrm{C}$ when it was photolized (>360 $\mathrm{m} \mu$ ), and then converted again to the sharp singlet spectrum after subsequent treatment at $-78^{\circ} \mathrm{C}$.

This photo-induced radical conversion could be interpreted tentatively as due to the following reactions analogous to the reaction 11 instead of the simple elimination of carbon monoxide molecules. ${ }^{30}$

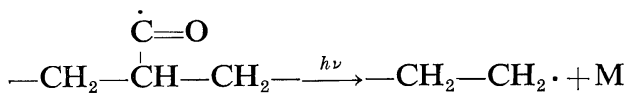

$\mathrm{M}$ is other nonparamagnetic products such as $\mathrm{O}=\mathrm{C}=\mathrm{CH}-\mathrm{CH}_{2}-$. Some $-\mathrm{CH}_{2}-\mathrm{CH}_{2}$. radicals would produce $-\mathrm{CH}_{2}-\dot{\mathrm{C}} \mathrm{H}-\mathrm{CH}_{2}-$ radicals according to the hydrogen atom abstraction reaction 7 .

The analogous change of ESR spectrum of 
UV-irradiated ketone has been reported by Hama, et al. ${ }^{61}$ and was attributed to the following mutual conversions:

$$
-\mathrm{CH}_{2} \dot{\mathrm{C}}-\underset{\mathrm{H}}{\stackrel{\mathrm{C}}{\mathrm{C}} \stackrel{\mathrm{O}}{\stackrel{\mathrm{O}}{\leftrightarrows}}} \stackrel{\mathrm{H}}{\longrightarrow}-\mathrm{CH}_{2}-\mathrm{CH}_{2}-\underset{\|}{\mathrm{C}} .
$$

The identification of free radicals, however, seems not to be conclusive.

Allylic Radicals. The allylic radicals did not show any change after UV-irradiation through a UV-39 filter. This is a remarkable contrast to allylic radicals produced in polyethylene irradiated by ionizing radiation. In the latter case, it is reported that alkyl radicals are produced after irradiation by UV-light through a UV-39 filter as follows. ${ }^{28}$

$$
\begin{gathered}
-\mathrm{CH}=\mathrm{CH}-\dot{\mathrm{C}} \mathrm{H}-\mathrm{CH}_{2}- \\
\stackrel{{ }_{h \iota}}{\longrightarrow}-\mathrm{CH}=\underset{\mathrm{CH}}{\mathrm{H}}-\mathrm{CH}-\mathrm{CH}=\mathrm{CH} \\
+\mathrm{CH}_{3}-\stackrel{i}{\mathrm{C}}-\mathrm{CH}_{2}-
\end{gathered}
$$

It can be supposed that the difference of trapping region of the allylic radicals may be a factor governing the reactivity of free radicals since allylic radicals seem to be trapped in different regions according to the method of formation either by UV-irradiation or high-energy radiation. In fact it is reported $^{62}$ that photoinduced radical conversions depend on the surrounding matrix.

Acknowledgement. The authors wish to express their gratitude to Drs. S. Kudama, T. Nishikida, and A. Segawa for their kind guidance and encouragement, and to Dr. Y. Kubota for his continued interest and helpful discussions.

\section{REFERENCES}

1. S. Ohnishi, S. Sugimoto, and I. Nitta, J. Chem. Phys., 39, 2647 (1963).

2. A. Charlesby and R. H. Partridge, Proc. Roy, Soc., Ser. A, 283, 329 (1965).

3. B. Rånby and H. Yoshida, J. Polym. Sci., Part C, 12, 263 (1966).

4. H. L. Browning, Jr., H. D. Ackermann, and H. W. Patton, ibid., Part A-1, 4, 1433 (1966).

5. B. Rånby and P. Carstensen, Advan. Chem. Ser., 66, 256 (1967).
6. K. Tsuji and T Seiki, Polym. Letters, 7, 839 (1969).

7. Y. Hama, Y. Furui, K. Hosono, and K. Shinohara, Rept. Progr. Polym. Phys. Japan, 12, 481 (1969).

8. K. Tsuji and T. Seiki, ibid., 13, 507 (1970).

9. K. Tsuji and T. Seiki, Polym. Letters, 8, 817 (1970).

10. K. Tsuji, K. Hayashi, and S. Okamura, $J$. Polym. Sci., Part A-1, 8, 583 (1970).

11. A. Charlesby and D. K. Thomas, Proc. Roy. Soc., Ser. A, 269, 104 (1962).

12. Y. Hama and K. Shinohara, J. Polym Sci., Part A-1, 8, 651 (1970).

13. R. H. Partridge, J. Chem. Phys., 45, 1679 (1966).

14. A. U. Munck and J. F. Scott, Nature. 177. 587 (1956).

15. H. Tsubomura and R. S. Mulliken, J. Amer. Chem. Soc., 82, 5966 (1960).

16. V. I. Stenberg, R D. Olson, C. T. Wang, and N. Kulevsky, J. Org. Chem., 32, 3327 (1967).

17. A. R. Burgess, Chem. Ind. (London), 78 (1952).

18. H. Hatano, M. Yanagita, Y. Fujita, and T. Kwan, Kogyo Kagaku Zasshi (J. Chem. Soc. Japan, Ind. Chem. Sect.), 72, 123 (1969).

19. F. H. Winslow, W. Matreyek, and A. M. Trozzolo, Polym. Preprints, 10 (2), 1271 (1969).

20. S. Siegel and H. Judeikis, J. Chem. Phys., 43, 343 (1965).

21. G. H. Hartley and J. E. Guillet, Macromolecules, 1, 165, 413 (1968).

22. M. Heskins and J. E. Guillet, ibid, 3, 224 (1970).

23. E. P. Sakaluskene, S. R. Rafikov, and Yu. A. Ershov, Trudy Akad. Nauk Lilovski SSR, Ser. $B, 1,79$ (1967).

24. A. R. Burgess, Natl. Bur. Standards, Circ., 525, 149 (1953).

25. J. E. Guillet, J. Dhanraj, F. J. Golemba, and G. H. Hartley, Advan. Chem. Series, 85, 272 (1968).

26. K. Tsuji and T. Seiki, J. Polym. Sci., Part-A, in press.

27. P. Yu. Butyagin, A. M. Dubinskaya, and V. A. Radtsig, Russian Chem. Rev., 38, 290 (1960).

28. S. Shimada, H. Kashiwabara, and J. Sohma, J. Polym. Sci., Part A-2, 8, 1291 (1970).

29. B. Eda, K. Nunome, and M. Iwasaki, Preprint, 13th Symposium of Radiation Chemistry, The Chemical Society of Japan and Japanese Society of Radiation Chemistry, 2-12, Tokyo, 1970, p 90.

30. S. Noda, K. Fueki, and Z. Kuri, J. Chem. Phys., 49, 3287 (1968). 


\section{K. TsujI and T. SeikI}

31. J. E. Bennett, B. Mile, and B. Ward, Chem. Commun., 13 (1969).

32. H. J. Judeikis and S. Siegel, J. Chem. Phys., 43, 3625 (1965).

33. R. C. McCalley and A. L. Kwiram, J. Amer. Chem., Soc., 92, 1441 (1970).

34. F. J. Adrian, E. L. Cochran, and V. A. Bowers, J. Chem. Phys., 36, 1661 (1662).

35. H. C. Lefkovitz, J. Fain, and F. A. Matsen, ibid., 23, 1690 (1955).

36. J. G. Galvert and J. N. Pitts, Jr., "Photochemistry" John Wiley and Sons, Inc., New York, N.Y., 1966, p 379.

37. V. A. Radtsig and P. Yu. Butyagin, Vysokomol. Soedin., Ser. A, 9, 2549 (1967).

38. T. Kawashima, M. Nakamura, S. Shimada, H. Kashiwabara, and J. Sohma, Rept. Progr. Polym. Phys., Japan, 12, 469 (1969); private communication from Mr. S. Shimada.

39. Y. Henriksen "Free Radical in Biological System" Academic Press, New York N.Y., London, 1961, p 279.

40. V. I. Tupikov, S. Ta. Phsezhetskii, J. Phys. Chem. (Russian), 38, 2430 (1964).

41. P. B. Ayscough, K. J. Ivin, and J. H. O'Donnell, Trans. Faraday Soc., 61, 1110 (1965).

42. K. Tsuji and T. Seiki, Submitted for publication.

43. M. L. Dannis, J. Appl. Polym. Sci., 1, 121 (1959).

44. A. T. Koritzky, Yu. M. Molin, V. N. Shamshev, N. Ya. Bouben, and V. V. Voevodsky, Vysokomol. Soedin, 1, 1182 (1959).

45. I. Auerbach, Polymer, 7, 283 (1966).

46. D. C. Waterman and M. Dole, J. Phys. Chem., 74, 1913 (1970).

47. S. Ohnishi, S. Sugimoto, and I. Nitta, J. Chem.
Phys., 37, 1283 (1962).

48. I. Nitta, Y. Ikeda, and S. Ohnishi, Ann. Rept. Japan Assoc. Radiat. Res. Polymers, 2, 203 (1960).

49. H. Kashiwabara, Japan. J. Appl. Phys., 2, 523 (1963).

50. P. Yu. Butyagin, I. V. Kolbanev, A. M. Dubinskaya, and M. U. Kislyuk, Vysokomol. Soedin., Ser. A, 10, 2265 (1968).

51. B. Eda, K. Nunome, and M. Iwasaki, Polym. Letters, 7, 91 (1969).

52. H. Fischer, K. H. Hellwege, and P. Neudörfl, J. Polym. Sci., Part A, 1, 2109 (1963).

53. H. Fischer, K. H. Hellwege, U. Johnson, and P. Neudörfl, Kolloid-Z., 195, 129 (1964).

54. S. Ohnishi, S. Sugimoto, and I. Nitta, $J$. Polym. Sci., Part A, 1, 605 (1963).

55. M. Neiman, T.S. Fedoseeva, G. V. Chubarova. A. L. Buchachenko, and Ya. S. Lebedov, Vysokomol. Soedin., 5, 1339 (1963).

56. K. Tsuji, T. Okaya, K. Hayashi, and S. Okamura, Ann. Rept. Japan, Assoc. Radiat. Res. Polymers, 8, 111 (1966/1967).

57. G. Czapski and L. M. Dorfman, J. Phys. Chem., 68, 1169 (1964).

58. S. Siegel and H. Hedgpeth, J. Chem. Phys., 46, 3904 (1967).

59. P. Hedvig, J. Polym. Sci., Part A-1, 7, 1145 (1969).

60. E. R. Klinshpont, V. K. Milinchuk, and S. Ya. Pshezhetskii, Vysokomol. Soedin., Ser. A, 12, 1505 (1970).

61. Y. Hama, and K. Shinohara, Mol. Phys., 18, 279 (1970).

62. H. Nishimura, N. Tamura, Y. Tabata, and K. Ohshima, Nippon Kagaku Zasshi (J. Chem. Soc., Japan, Pure Chem. Sect.), 91, 787 (1970). 